\title{
ETHNOPSYCHOLOGICAL PECULIARITIES OF SOCIAL INTELLIGENCE OF HIGH SCHOOL STUDENTS WITH DIFFERENT TYPE OF PICTURE OF THE WORLD
}

Mariya A. Vyshkvyrkina, Academy of Psychology and Educational Sciences, Southern Federal University, Rostov-na-Donu, Russian Federation.

\section{Introduction}

A relatively new, but relevant trend in psychology is the study of social intelligence. Various aspects of the problem of social intelligence are reflected in the works of G. Ayzenk, L.I. Antsiferova, N.V. Bachmanova, M.I. Bobneva, X. Gardner, V.N. Druzhinin, K.A. Kudryavtseva, V.N. Kunitsyna, V.A. Labunskoy, G. Lyman, R. Loumana, E.S. Mikhailova, R. Sternberg, D.V. Ushakova, E.A. Fedorova, N. Frederickson, M.A. Kholodnoy, O.B. Chesnokova, A.L. Yuzhaninova, et al. At the same time, studies of the ethnopsychological features of social intelligence are practically not presented.

On the other hand, in psychological science, a rather specific situation has developed around the category "image of the world": the study of this category has so far been carried out only in general terms (E.Yu. Artemyeva, E.L. Dotsenko, A.A. Leontyev, D.A. Leontyev, V.F. Petrenko, V.V. Petukhov, S.D. Smirnov, A.P. Stetsenko, Yu.K. Strelkov, A.G. Shmelev and others), special works built on empirical material and aimed at solving specific applied problems are practically absent.

Of particular interest is the study of the peculiarities of ideas about the world, other people and yourself among high school students of different nationalities, as well as the study of the ability to interact adequately and successfully with other people, the social environment, sometimes requiring non-standard decision-making, correct interpretation, prediction of interpersonal situations.

In this regard, the goal of our research is to identify the ethnopsychological features of the social intelligence of high school students with different types of world view.

Materials and Methods

Base research: students grades 9-11 at the age of 15-17 years. Of these, 54 Russian-born schoolchildren and 42 are Meskhetian Turks living in the city of Rostov-on-Don.
The study used the methods of research of social intelligence Guilford-Sulliven (in adaptation by AS Mikhailova (Aleshina) and the test "Picture of the World" (ES Romanova, OFF Potemkin).Statistical data processing included descriptive statistics, the Mann-Whitney U-test. Results

In the group of Russian high school students the landscape picture of the world is most often encountered $(57.1 \%), 14.3 \%$ of respondents each represented the world around them either in abstract forms or in metaphorical ones. The planetary picture of the world, as well as the immediate environment, is found in $7.1 \%$ of cases.

In $65.0 \%$ of cases, senior Meskhetian Turks paint a "landscape" picture of the world, $15 \%$ of respondents have a planetary, $10.0 \%$ metaphorical and 5\% each has an abstract or immediate environment.

As a result, our empirical study revealed the features of social intelligence of high school students of different nationalities with the same picture of the world:

- high school students of Russian and Turkish nationalities with a landscape picture of the world are well aware of the links between people's actions and their consequences, orienting themselves in generally accepted norms and rules of behavior, understand the states, feelings, intentions of people by non-verbal manifestations, the ability to grasp the meaning of non-verbal reactions when interpreting situations of communication, and understand the nature of human relationships and correctly interpret the words of the interlocutor, depending on the context of the situation;

Russian high school students with a landscape picture of the world, in comparison with high school students-Turks, better predict the development of the situation, and more accurately predict the consequences of the behavior of the interaction participants, which is confirmed by the results of statistical analysis:

high school students-Turks with a metaphorical picture of the world, in comparison with Russian high school students, better understand the connection between people's actions and their consequences, are able to anticipate interpersonal events, they are wellversed in generally accepted norms and rules of behavior, they understand well the states, feelings and intentions of people for non-verbal manifestations, as well as better oriented in the nature and shades of human relationships and more accurately predict the dynamics of interpersonal relationships.
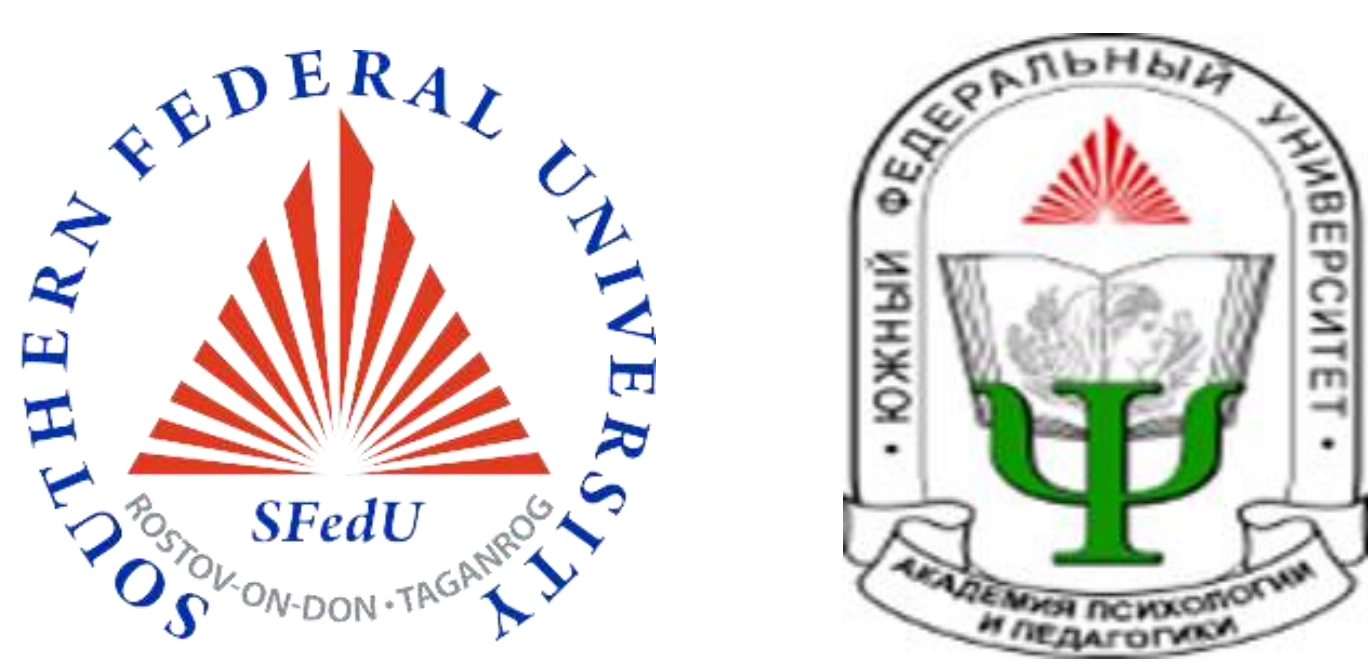

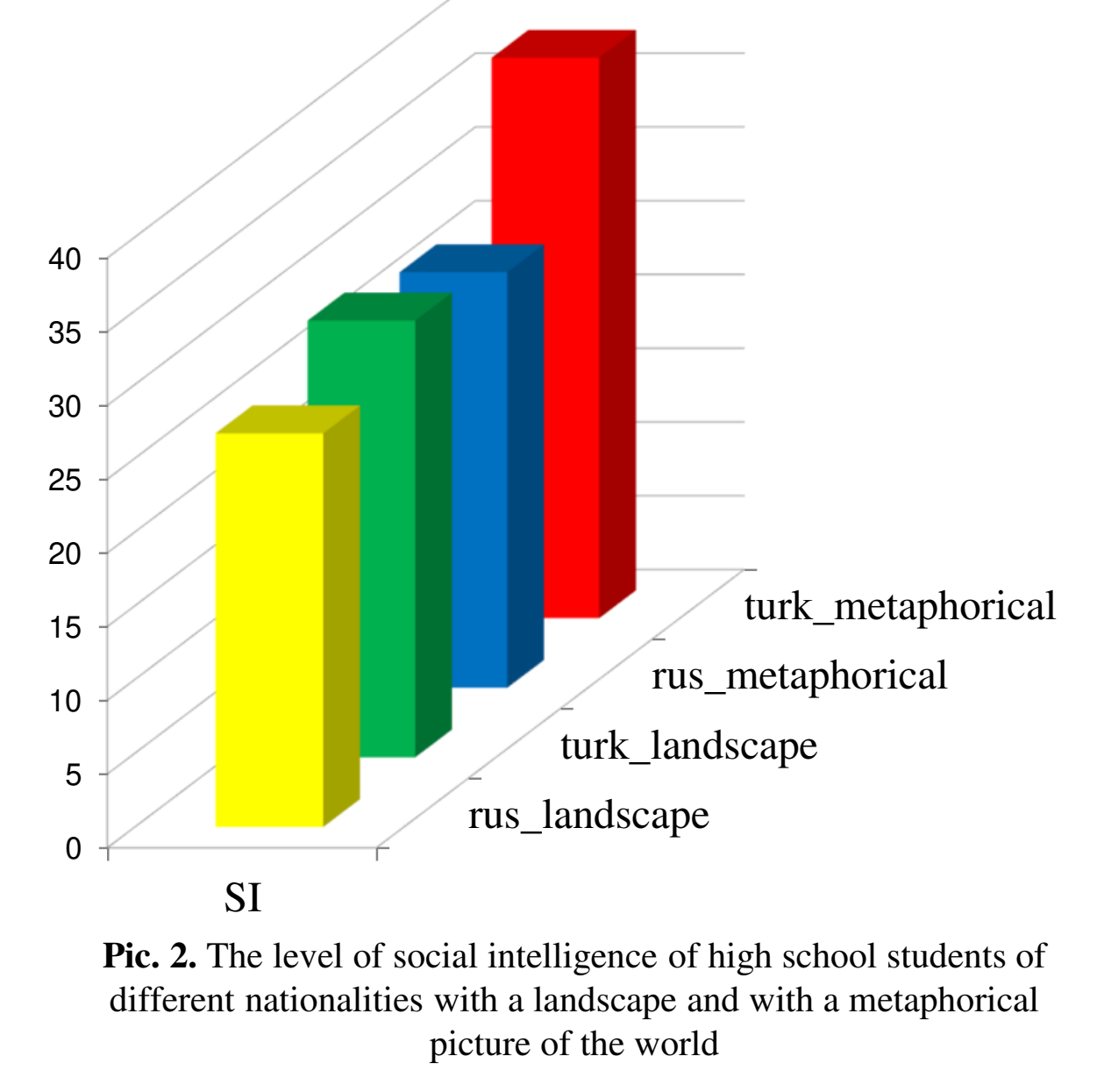

Tab. 1. Indicators of the significance of differences in the degree of expression of the components of social

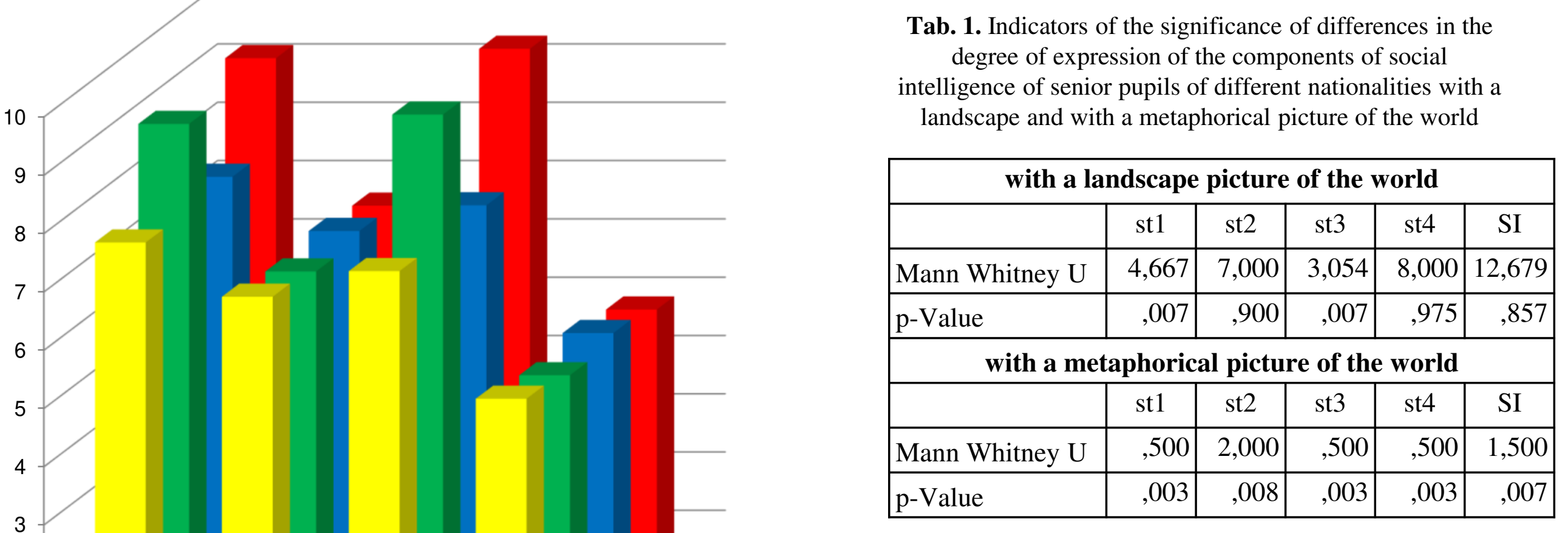

turk_metaphoric rus_metaphorical 01 turk_landscape

st1 $\quad$ st2 $\quad$ st3 $\quad$ st 4

Pic. 1. The severity of the social intelligence components of high school students of different nationalities with a landscape and with a metaphorical picture of the world 